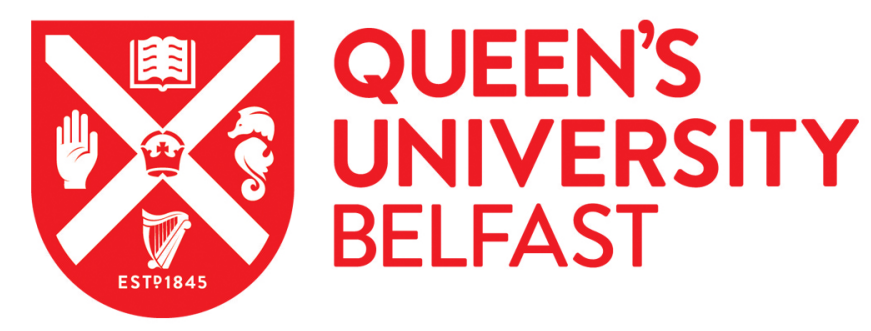

\title{
Assessing the Novel Aircraft Lightning Strike Protection Technology Using Technology Impact Forecasting
}

Huang, Y., Sun, D., \& Soban, D. (2020). Assessing the Novel Aircraft Lightning Strike Protection Technology Using Technology Impact Forecasting. Journal of Aircraft. https://doi.org/10.2514/1.C035875

Published in:

Journal of Aircraft

Document Version:

Peer reviewed version

Queen's University Belfast - Research Portal:

Link to publication record in Queen's University Belfast Research Portal

Publisher rights

Copyright 2020 American Institute of Aeronautics and Astronautics. This work is made available online in accordance with the publisher's policies. Please refer to any applicable terms of use of the publisher.

\section{General rights}

Copyright for the publications made accessible via the Queen's University Belfast Research Portal is retained by the author(s) and / or other copyright owners and it is a condition of accessing these publications that users recognise and abide by the legal requirements associated with these rights.

Take down policy

The Research Portal is Queen's institutional repository that provides access to Queen's research output. Every effort has been made to ensure that content in the Research Portal does not infringe any person's rights, or applicable UK laws. If you discover content in the Research Portal that you believe breaches copyright or violates any law, please contact openaccess@qub.ac.uk. 


\title{
Assessing the Novel Aircraft Lightning Strike Protection Technology Using Technology Impact Forecasting
}

\author{
Ying Huang, ${ }^{1}$ Dan Sun. ${ }^{2}$, Danielle S. Soban ${ }^{3}$ \\ Queen's University Belfast, Belfast, BT7 1NN, United Kingdom.
}

Carbon fiber reinforced polymer (CFRP) composites are widely used in aircraft structures due to its excellent mechanical properties, lightweight and corrosion resistance compared to conventional metallic materials. However, the low electrical conductivity in the composites thickness direction makes them susceptible to lightning strike damage. An all-polymeric lightning strike protection (LSP) system based on conductive polymer (polyaniline) adhesive layer has been proposed in the recent literature. Preliminary study suggests the polyaniline based adhesive layer has good electrical conductivity, low density, easy applicability and corrosion resistance, which make it a strong contender for next generation LSP solution. However, being a novel technology with low technical readiness level (TRL), its impact on the aircraft weight, cost and performance remains unknown. In this work, technology impact forecasting (TIF) has been deployed for the first time to explore the potential impact of the novel LSP technology in the context of a commercial aircraft system. This work presents a rapid assessment on the feasibility and economic viability of the novel LSP technology and the results has been compared with the traditional metal mesh and the more widely used expanded metal foil LSP technologies. The results from this study show that although the parasitic weight of the conductive polymer is lower than that of the metal mesh, the expanded metal foil is still a better option in terms of weight saving. From the economic perspective, the proposed new technology could lead to greater profitability in research, development, testing and evaluation cost. However, this is compromised by the increased costs in manufacturing and maintenance of such new material technology.

\section{Nomenclature}

$\begin{array}{ll}\text { CFRP } & =\text { Carbon Fiber Reinforced Polymer } \\ T I F & =\text { Technology Impact Forecasting } \\ T R L & =\text { Technology Readiness Level } \\ R S E & =\text { Response Surface Equation } \\ D O E & =\text { Design of Experiment } \\ \text { PANI } & =\text { Polyaniline } \\ D B S A & =\text { Dodecyl benzenesulfonic acid } \\ D V B & =\text { Divinylbenzene } \\ \text { FLOPS } & =\text { Flight Optimization System } \\ \text { ALCCA } & =\text { Aircraft Life Cycle Cost Analysis }\end{array}$

\section{I.Introduction}

\section{A. Aircraft lightning strike protection}

Carbon fiber reinforced polymer (CFRP) composites are widely used in aircraft structures, such as wings, fuselage, stabilizers and turbine housings, due to their high specific strength/stiffness, light weight and corrosion resistance compared to conventional metallic materials[1]. However, the low electrical conductivity in the composite thickness

\footnotetext{
${ }^{1} \mathrm{PhD}$ Student, School of Mechanical \& Aerospace Engineering, AIAA Student Member

${ }^{2}$ Lecturer, School of Mechanical \& Aerospace Engineering

${ }^{3}$ Lecturer, School of Mechanical and Aerospace Engineering, Senior Member AIAA.
} 
direction makes them susceptible to lightning strike damage. The highly concentrated lightning current (up to 200,000 A [2]) in lightning strikes can cause serious damage on composite structures as a result of Joule heating, matrix resin decomposition, acoustic shock and magnetic force effect, etc. [3][4].

To ensure the aircraft safety during its operation, highly efficient lightning strike protection (LSP) is essential for CFRP-based aircraft. The role of LSP is to provide a conductive path on the outer surface of the airplane for the lightning current to flow through the aircraft without causing serious damage [5]. The common LSP solutions in aerospace industries include bonding metallic (e.g. aluminum or copper) mesh or foil to the composite structure as an outer laminate ply or incorporating conductive material into the composites to enhance its overall electrical conductivity. For example, metallic foils were deployed for aircraft composite panels for Airbus A350 XWB [6] and Boeing 787 Dreamliner [7], while nonwoven copper mesh has been used as LSP for Adam A700 [8]. Although these methods can efficiently protect the aircrafts from concentrated lightning energy, the high density of the metals (167.9 $\mathrm{lb} / \mathrm{ft}^{\wedge} 3$ for aluminum and $557.5 \mathrm{lb} / \mathrm{ft}^{\wedge} 3$ for copper [5]) brings weight penalty to aircraft which in turn generates additional cost. In addition, metal-based LSP has other limitations such as low adhesion at the metal-polymer interface, potential galvanic corrosion (particularly for aluminum-based foil), uneven surface, etc. To address these limitations, some researchers have proposed new LSP solutions where conductive polymers were incorporated into the epoxy matrix to increase the electrical conductivity of CFRP structures. For instance, the electrical conductivity of CFRP (especially in its thickness direction) can be enhanced by mixing an intrinsic conductive polymer polyaniline(PANI) with epoxy when preparing the CFRP matrix [9][10][11]. Although the electrical conductivity of CFRP can be increased by 20 -fold, such technology suffers from a major limitation in terms of compromised CFRP mechanical properties. The tensile test of PANI/epoxy composites is three times lower than that of the typical epoxy used in the aircraft industry [12].

Today, expanded metal foil are increasingly used for LSP in composites aircraft structures. The expanded foils are fabricated from solid metal foils, which is then perforated and stretched to form diamond-shaped grids to allow for better draping over compound curves during bonding to a composites structure [13]. Expanded foil is considered as a good candidate in LSP due to their anisotropic electrical conductivity characteristics. Reviews of literature show that the extent of lightning strike damage is much less when the structure is protected with such a conductive layer [14]. Despite the lower aerial weight of these expanded foils (e.g.0.015 0.029 $\mathrm{lb} / \mathrm{ft}^{\wedge} 2$ [14]), a structural adhesive film is required to increase the adhesion at a metal-polymer interface, which inevitably introduces parasitic weight. 
Recently, Kumar et al [15] developed a novel, all-polymer based LSP system based on a conductive polymer adhesive layer. A mixture of polyaniline (PANI), dodecylbenzenesulphonic acid (DBSA) and a cross-linked polymer, divinylbenzene (DVB) was used to prepare a PANI-based adhesive conductive resin, which was subsequently applied on the surface of CFRP before curing [15]. The density of the prepared PANI-based LSP layer is only around 1.0-1.1 $\mathrm{g} / \mathrm{cm}^{\wedge} 3\left(62.4 \sim 68.7 \mathrm{lb} . / \mathrm{ft}^{\wedge} 3\right)$ and it does not cause corrosion issues. Results show that the electrical conductivity of the PANI-based LSP layer can achieve as high as $100 \mathrm{~S} / \mathrm{m}$ in all directions, much greater than that of the unprotected CFRP $(0.22 \mathrm{~S} / \mathrm{m}$ in thickness direction). Experimental results show that such LSP system can effectively dissipate simulated lightning current up to $100 \mathrm{kA}$ while retaining $100 \%$ residual strength of CFRP, giving a similar performance to that of metal-based LSP solution. Therefore, it has been considered as a very strong contender for next generation LSP technology.

\section{B. Technology Impact Forecasting Methodology}

Technology Impact Forecasting (TIF) employs modelling and simulation as the center element to identify, understand and quantify the potential impact of technology (technologies) in a probabilistic fashion [16]. It provides the decision-maker with ability to rapidly assess the feasibility and economic viability of the proposed technology with accuracy and speed. It also provides useful information for selecting appropriate technology in the absence of sophisticated, time-consuming mathematical formulation for project resource allocation[17]. TIF methodology uses several probabilistic tools, such as Design of Experiment (DoE), Response Surface Equations (RSEs) and Monte Carlo Simulation, to facilitate the assessment of new technologies. The system effectiveness that results from the infusion of a new technology is quantified through measuring changes, both positive and negative, in independent system level metrics (also referred to as system responses). However, the traditional aircraft sizing/synthesis tools are based on existing aircraft configuration and historical databases that limits their application to the new technology. The solution is to introduce a technology metric $\mathrm{k}_{-}$factor, into the analysis or sizing tool to assess the impacts of a new technology on system attribute [18]. In other word, these $\mathrm{k}_{-}$factors act as the disciplinarian metric multipliers that modify the disciplinary metrics (either enhancement or degradation) of the associated with new technology. Technologies are modelled by recognizing the uncertain value of $\mathrm{k}$ ffactor based on the available information on the readiness level of the technology and subsequently assigning an appropriate probability distribution to that $\mathrm{k}$ factor to develop a confidence estimate. The range (i.e., design space) and shape (i.e., shape function) of k_factors are based on: (i) quantitative data from literature reviews and (ii) qualitative data from technology expert opinions. When applying TIF 
to an aircraft system, all system responses are modelled by a physics-based aircraft sizing and synthesis code FLOPS (Flight Optimization System)[18]/ALCCA (Aircraft Life Cycle Cost Analysis) [19]. This code, when combined with the TIF method, is capable of calculating the effects of certain technology on the aircraft geometry, weight, aerodynamics, propulsion, mission and detail of aircraft life cycle cost, which in turn determine the feasibility and economic viability of the technology. The result from TIF is not a simple number, but, rather, is a probability distribution. The decision supportability aspects to new technologies are dependent on these probability distributions. For instance, if the result does not meet the confidence level set by the decision maker (i.e., technology not ready), it will provide quantitative results for decision makers to justify their decision in the early stage of the design.

Conventionally, TIF was mainly used for technologies with mid-Technology Readiness Level (TRL). In this work, we report apreliminary study where TIF is applied for the first time for a low TRL technology, i.e., PANI-based adhesive layer as novel LSP solution, in the context of a commercial aircraft system. The feasibility of using TIF to explore the impacts of the novel LSP technology on the wing of a representative commercial aircraft will be investigated. The potential benefit and penalty associated with the use of this new LSP technology compared to the traditional metal mesh and more widely used expanded metal foil LSP will be discussed.

\section{Test case}

In this study, a new mathematical model has been created to capture and quantify the impact of the PANI-based LSP layer in a complex aircraft system. The effect of a composite composition on the aircraft weight and the subsequent impacts on the aircraft cost will be discussed.

\section{A. Modelling Environment}

The materials information were obtained from published work [15][20] and has been listed in Table 1. 
Table 1 Materials information to be used for the present model.

\begin{tabular}{|c|c|c|}
\hline LSP layer Constituents & $\begin{array}{c}\text { Weight \% } \\
\text { (within the } \\
\text { polymeric LSP } \\
\text { layer) }\end{array}$ & $\begin{array}{c}\text { (Price } \\
\text { (USD/kg) }\end{array}$ \\
\hline Polyaniline (PANI) & $9 \sim 21 \%$ & 2.27 \\
\hline $\begin{array}{c}\text { Dodecyl benzenesulfonic acid } \\
\text { (DBSA) }\end{array}$ & $21 \sim 49 \%$ & 0.59 \\
\hline Divinylbenzene (DVB) & $30 \sim 70 \%$ & 2.27 \\
\hline
\end{tabular}

Fig.1 shows the multiscale synthesis modelling environment used for this study. Three models are considered in this work, namely, material model, wing model and aircraft model. Each model has its own set of algorithms, database and relationships. The material model was created by authors of the present work through Visual Basic Software within Microsoft Excel, database was collected from published work $[15,20] .$. The inputs for material model are the features of each constituent material within the composite as listed in Table 1. The outputs of the material model include weight, cost and property of the finished multi-functional composites, which were subsequently propagated upward and ultimately fed into the aircraft levels of the system performance. The price of the materials (as listed in Table 1) may vary as the scale of the material processing/manufacture changes.

Due to limited fidelity within the aircraft model for new materials concept, an additional wing model has been extracted from the aircraft model. The wing model takes the outputs from the material model as the inputs to conduct its analysis and generate outputs (e.g., wing weight, wing cost, wing performance, etc), which will in turn, serve as the inputs into the aircraft model without loss of compatibility with the aircraft model. The aircraft synthesis model used in this study is FLOPS. This model has the ability to resize the aircraft subject to a given input to meet the design mission. Results are presented in the form of a basic text output file, containing a list of weights, geometric and performance characteristics of the specific aircraft, which are linked with ALCCA to conduct economic analysis. A user created shell script can be used as interlinkage to link each model, which facilitates automatic multiple runs and allow quick change of input variables.

Once these models are created and populated, it represents an elaboration of the independence-interdependence framework to conduct rapid trades, change assumptions and requirement for different material concept. Any changes 
in the material model can thus be propagated through the wing model all the way up to the aircraft model to measure the performance of proposed material on the aircraft system. Instead of optimizing an aircraft, the impact of material selection and trade-offs can be made between wing model and material model without having to run sophisticated, time-consuming aircraft model. By allowing variation of inputs in the material model, the designer or decision-maker can explore the impacts of their choices and then make decisions, in real time.

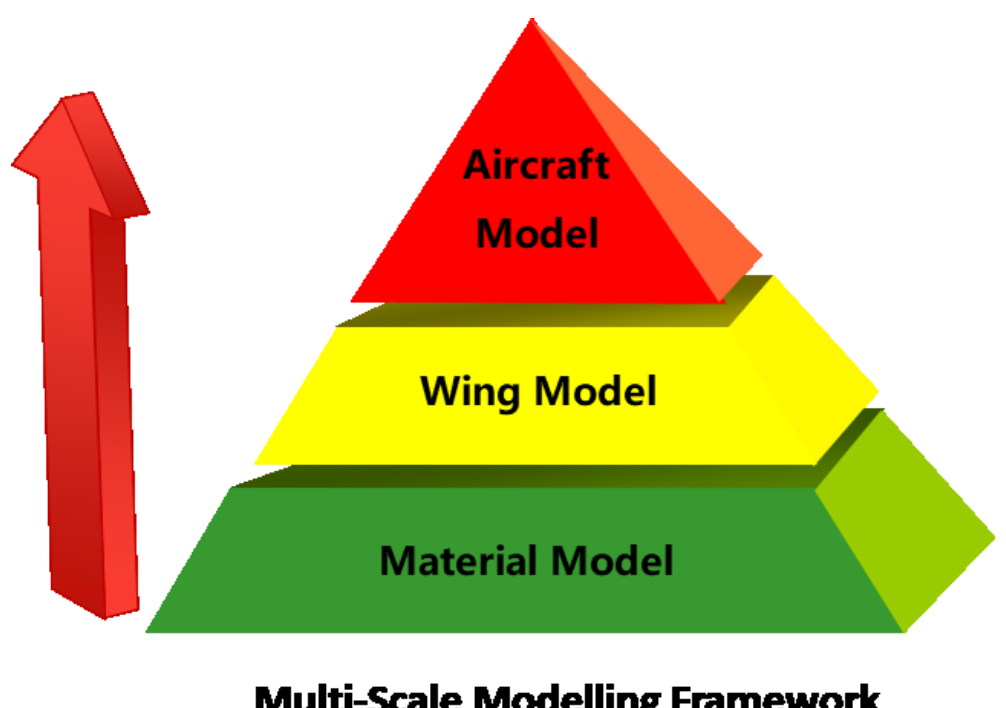

Fig. 1 Multi-Scale Modelling Framework of Technology Impact Forecasting.

\section{B. Aircraft Baseline}

The aircraft baseline configuration used for this study is a short-medium range commercial transport aircraft, Airbus A320. The baseline aircraft configuration examined in this study was assumed for a 1600 nautical miles mission with the maximum cruising altitude of $35,000 \mathrm{ft}$ at Mach number 0.78 . The payload of aircraft was assumed to be 150 passengers and their baggage, two flight crew and four flight attendants, two wing-mounted engines, and a fuselage length and diameter of $132.39 \mathrm{ft}$ and $13.6 \mathrm{ft}$, respectively. The mission has been divided into taxi out, climb to maximum altitude and cruise at Mach 0.78, and finally descend and land to the destination airport as shown in Fig. 2. The basic aircraft parameters are listed in Table 2. 
Table 2 Baseline aircraft parameters

\begin{tabular}{|c|c|c|}
\hline Parameter & Baseline & Unit \\
\hline Take-off Gross Weight & 154939.9 & $\mathrm{lbs}$ \\
\hline Thrust-to-weight ratio & 0.3 & - \\
\hline Wing area & 1330 & $\mathrm{ft} \wedge 2$ \\
\hline Wing aspect ratio & 9.39 & - \\
\hline Wing sweep & 25 & degree \\
\hline Wing span & 117.5 & $\mathrm{ft}$ \\
\hline Wing taper ratio & 0.24 & - \\
\hline utilization & 3800 & $\begin{array}{c}\text { block } \\
\text { hour/year }\end{array}$ \\
\hline Number of climbs & 1 & - \\
\hline Climb minimum Mach number & 0.3 & - \\
\hline
\end{tabular}

A320 is the first subsonic aircraft to incorporate composite primary structure [21], which constitute 28 percent of the weight of the A320 airframe[22]. Another unique feature of the A320 configuration is its ability to reduce the fuel consumption through use of a sharklet blended winglet [23]. Although the $2.4 \mathrm{~m}(7.8 \mathrm{ft})$ high device adds $200 \mathrm{~kg}$ (440lb) additional weight, it reduces about 3.5\% fuel consumption on flights greater than 1,739.8 mile (1511.88 nautical mile)[24]. Since composites constitute $28 \%$ of the weight of the A320 airframe [22], the percentage of composite materials used in a wing structure is estimated to be $28 \%$ in this study.

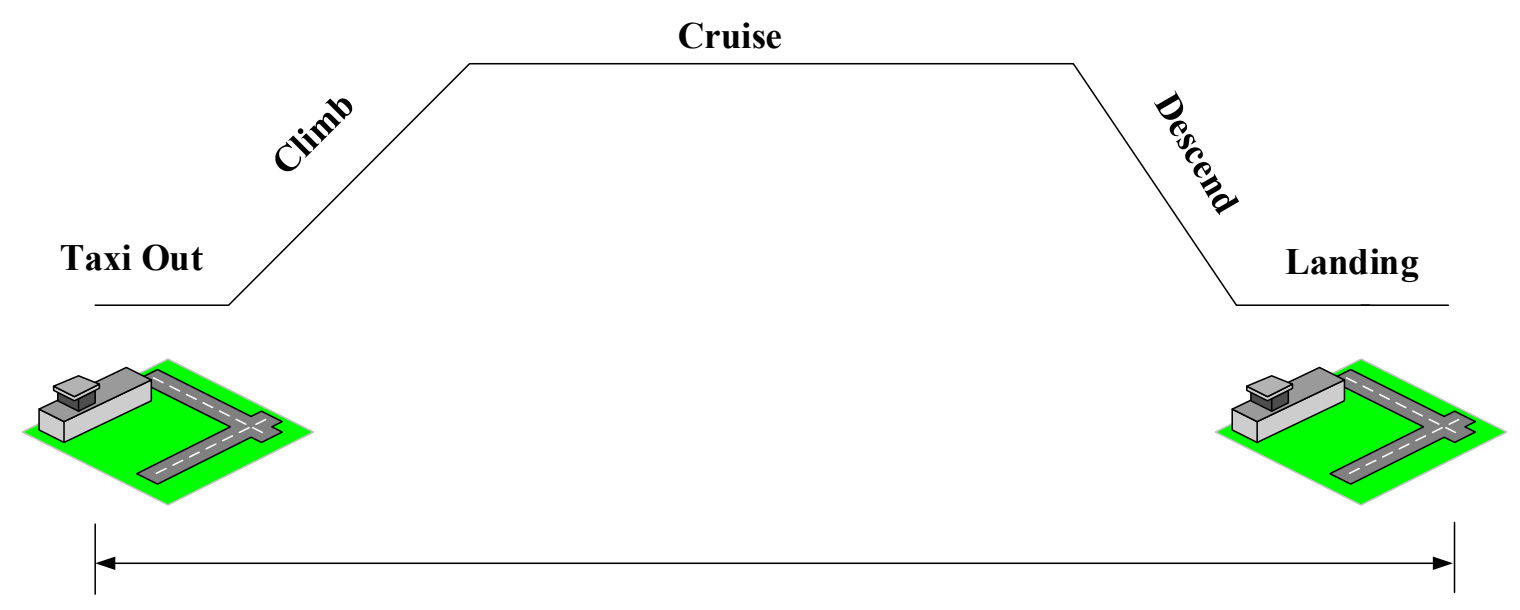

1600 Nautical Miles

Fig. 2 Baseline Mission Profile.

\section{Design Variables and System Responses}




\section{Variable Selection}

TIF methodology introduces a multiplicative factor, $\mathrm{k}_{-}$factor, into the analysis to represent impacts of a new technology on system responses, either benefit or penalty. The ranges for each k_factor represent the boundaries of the design space with respect to the new technology (i.e., PANI-based LSP layer). As mentioned early, PANI-based LSP layer is applied onto conventional CFRP panels, to replace the metal mesh for LSP purpose. Therefore, changes in wing weight were considered as an important $\mathrm{k}_{-}$factor. Serval other complexity factors were also considered as k_factors due to the increased complexity in processing, fabrication, assembly, tooling equipment associated with the addition of new technologies. By using these factors, the improvement or degradation caused by the proposed technology and the corresponding cost increase or decrease can be quantified. Although these complexity factors have significant influence on the final aircraft cost, it is difficult to predict the uncertainties affecting these factors since each manufacture have their own method for estimating the value of these factors in relation to their particular method of production. Therefore, the primary assumptions were established based on published studies [25][26]. The factors of learning curve were also used to account the introduction of new skills for engineers and labors to predict the cost required for future cycles of a construction activity. The values of learning curve were assumed following reference [27]. A specific k_factor MMC (maintenance man-hour per block hour changed by using this PANI-based LSP layer) is used to model the change in man-hour needed per block hour for maintenance with respect to this new technology based on subjective experience. It is worth mentioning that the baseline within Table 3 is calculated through FLOPS without using any conductive material on the wing structure. The minimum and maximum values of the wing weight are the delta value with respect to the impact on wing weight as a result of incorporating new LSP material. Table 3 outlines all the $\mathrm{k}_{-}$factors used in this study.

Table 3 K_factors and ranges of variability examined for PANI-based LSP layer

\begin{tabular}{|c|c|c|c|c|}
\hline Design Variables & Variable & Baseline & Minimum & Maximum \\
\hline Wing Weight (lbs.) & $\begin{array}{c}\text { K_Wing } \\
\text { Weight (lbs.) }\end{array}$ & 13653.6 & 13759.37 & 13768.92 \\
\hline $\begin{array}{c}\text { Complexity factor for composites wing } \\
\text { structure basic design engineering }\end{array}$ & K_CFWCO & 1 & $-5.00 \%$ & $20.00 \%$ \\
\hline $\begin{array}{c}\text { Complexity factor for composites wing } \\
\text { tooling and factory test equipment }\end{array}$ & K_CFWCOTF & 1 & $-5.00 \%$ & $20.00 \%$ \\
\hline
\end{tabular}




\begin{tabular}{|c|c|c|c|c|}
\hline $\begin{array}{c}\text { Wing structure composites complexity } \\
\text { factor }\end{array}$ & $\begin{array}{c}\text { K_CFWINGC } \\
\text { O }\end{array}$ & 0.502 & $-5.00 \%$ & $20.00 \%$ \\
\hline Airframe Learning Curve Factor & K_LEARN & 82 & 87 & 90 \\
\hline Assembly Learning Curve Factor & K_LEARNAS & 82 & 87 & 90 \\
\hline $\begin{array}{c}\text { Maintenance man-hours per block hour } \\
\text { changed by using this PANI-based LSP } \\
\text { layer }\end{array}$ & K_MMC & 0 & $-7 \%$ & $7 \%$ \\
\hline
\end{tabular}

\section{Responses of Interest}

The assessment of a new technology must be addressed through the system responses they affect. In the probabilistic design, the system response is represented by probability distributions, either a probability density function (PDF) or a cumulative distribution function (CDF). By comparing the PDF or CDF to the baseline value, the decision-maker can be informed of the risk in the design phase. In this study, a list of specific responses associated with aircraft size and cost have been selected. These responses are highly likely to be influenced by the implementation of the proposed new technology and the details can be found in Table 4.

Table 4 Responses of interests for aircraft system.

\begin{tabular}{|c|c|l|}
\hline & $\begin{array}{c}\text { Response } \\
\text { Variable }\end{array}$ & \multicolumn{1}{c|}{ Description } \\
\hline \multirow{4}{*}{$\begin{array}{c}\text { Aircraft } \\
\text { Size }\end{array}$} & TOGW & Take-off Gross Weight (in pounds) \\
\cline { 2 - 3 } & OEW & Operating empty weight (in pounds) \\
\cline { 2 - 3 } & FUEL WT & Fuel Weight (in pounds) \\
\cline { 2 - 3 } & W/S & Wing Loading (in pounds per square foot) \\
\cline { 2 - 3 } & THRUST & Engine Thrust (in pounds) \\
\hline \multirow{4}{*}{$\begin{array}{c}\text { Aircraft } \\
\text { Cost }\end{array}$} & RDT\&E & $\begin{array}{l}\text { Research, Development, Testing and Evaluation Cost (in millions of } \\
\text { USD }\end{array}$ \\
\cline { 2 - 3 } & OSC & Operation and Support Cost (in millions of USD) \\
\cline { 2 - 3 } & FUC & First Unit Cost (in millions of USD) \\
\cline { 2 - 3 } & AUAC & Average unit airplane cost (including spares) (in millions of USD) \\
\hline
\end{tabular}

\section{Creating Surrogate Models}

Having defined the k_factors and the corresponding responses, a Response Surface Equation (RSE) was used to create surrogate models of the FLOPS sizing and synthesis code. RSEs were created by running the variable 
combinations through the Design of Experiments (DoE). A statistical analysis software JMP [28] was used to perform the regression analysis and create RSEs.

The modern aircraft system is extremely complex, and most system responses of interest are a function of hundreds of design variables. By using surrogate models, the relative contributions of various design variables to the selected system response can be clearly identified through a simple polynomial equation. Once the designer has a new set of variables within the design space, these new data can be inserted into pre-defined RSEs and the corresponding value of the responses can be calculated instantaneously through RSEs without having to recreate the equation or run further synthesis code. The equations represent a quick, accurate way of determining a response for the given values of variables as long as these values are within the range of variables for which the RSE is defined. With the generation of the surrogate models in the form of RSEs, the TIF methodology continues with the infusion of uncertainty and risk. Firstly, each design variable represented by the $\mathrm{k}_{-}$factor was assigned a probabilistic distribution (i.e. shape function) over the range addressed for the RSEs. Due to the low TRL of the technology, all k_factors were assigned a default uniform shape function with minimum and maximum values. Figure 3 illustrates the uniform shape functions used for the new technology, with the range of the wing weight defined in Table 3. A Monte Carlo simulation was then conducted, based on the shape functions given.

K_Wing Weight (lbs)

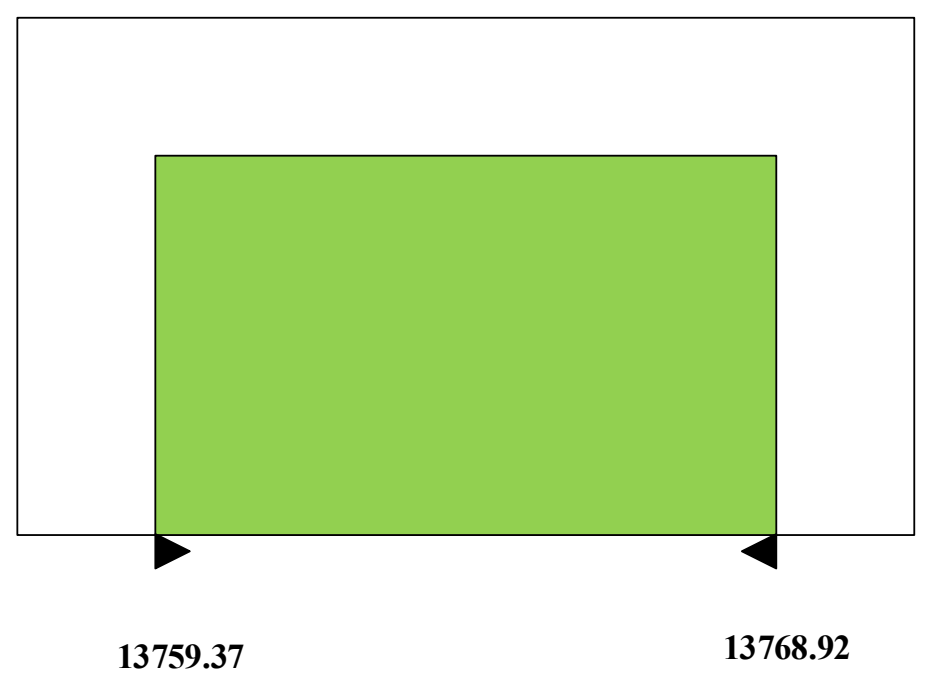

Fig. 3 Uniform shape function of $\mathbf{k}_{-}$factor values for learning curve. 


\section{E. Results and Discussions}

Figure 4 shows the "prediction profiler", which provides interactive visualization of the design space on the sensitivities of the responses to all the design variables. The gradient and direction of the hairlines (green and red dashed lines) indicate the sensitivity of the response to a design variable and its influence (positive or negative). The value of $\mathrm{k}$ _factor can be manipulated by moving the hairline within the range, and corresponding value of responses can be updated instantaneously through the RSEs. 


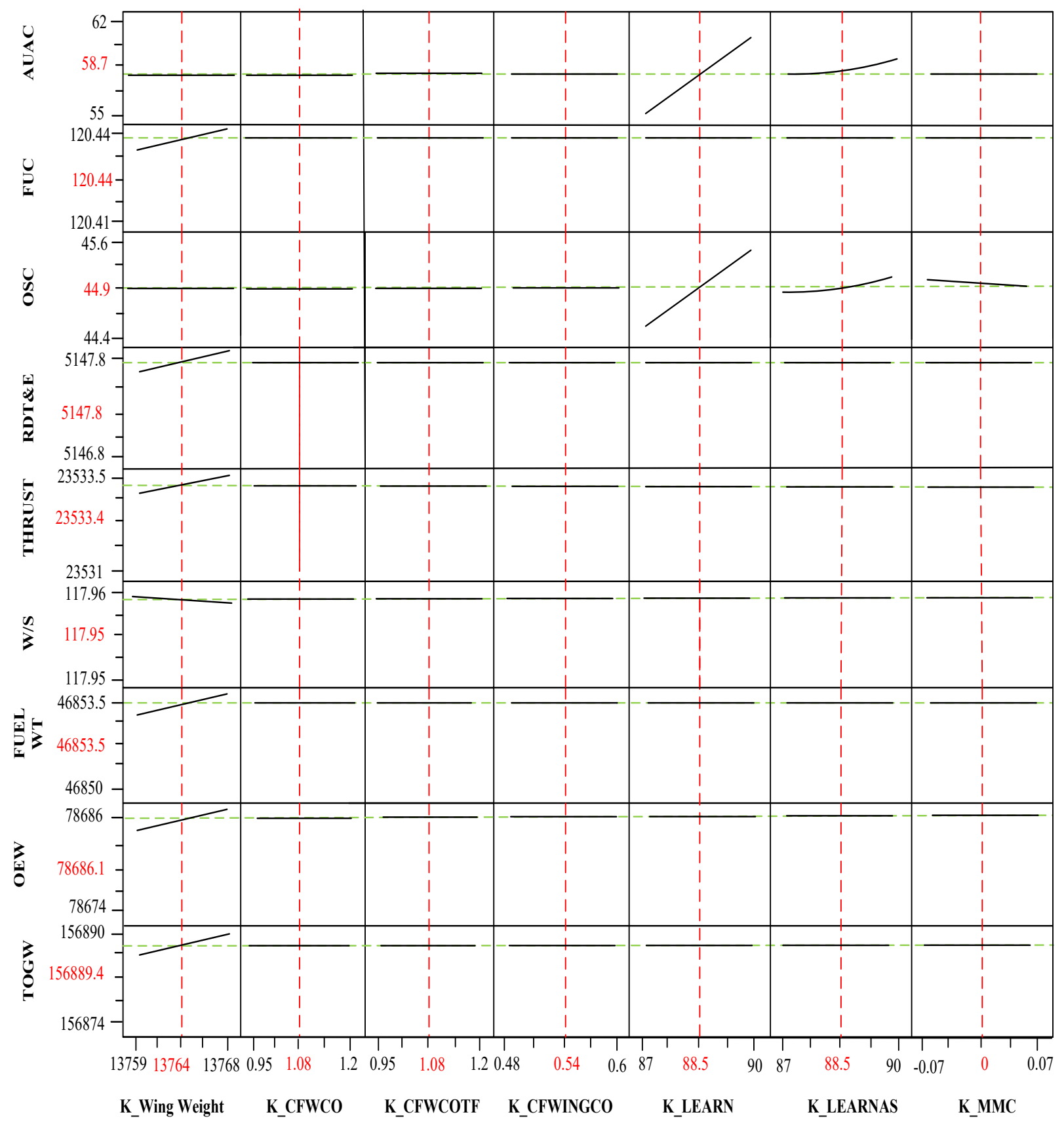

Fig. 4 Prediction Profile of using PANI-based LSP layer for aircraft system

The sensitivities of the responses to each $\mathrm{k} \_$factor can be identified from Fig. 4. For example, a change in wing weight (k_wing weight) will have a major influence on most of the system responses (curve gradient). This is because, FLOPS/ALCCA is a weight-driven program, extensive use of PANI-based LSP layer on an aircraft may significantly increase the structural weight, therefore, the corresponding system responses relating to aircraft size and cost both increased. The key effects on aircraft cost are those variables that are associated with the learning curve (k_LEARN 
and k_LEARNAS) of the aircraft. It can be seen that the operation support cost (OSC) and the average unit airplane cost (AUAC) have the highest degree of sensitivity to k_LEARN and k_LEARNAS because it shows the highest degree of curve deflection. This makes sense as with the increased complexity in material and labor associated the new LSP technology (e.g., particular regions, dimensions, tolerances, surface finishes, etc), the corresponding operation support cost and average unit airplane cost will increase. None of the complexity factors (k_CFWCO, k_CFWCOTF and k_CFWINGCO) have significant impact on the responses. This suggests that although the use of PANI-based LSP layer may increase complexity for manufacturing process, the range of increase only has a negligible impact on the overall aircraft system responses. The system response in relation to aircraft size is given as cumulative distribution function (CDF), as is shown in Fig. 5. The influence of PANI-based LSP layer (through application of the $\mathrm{k} \_$factors) on the aircraft system is examined through these CDFs. In this study, the impact of PANI-based LSP layer is evaluated by comparing it with traditional metal mesh and the widely used expanded metal foil. In Fig. 5, the red and blue lines indicate two different baselines (the initial value of the system response) for traditional metal mesh and expanded metal foil, respectively. The black line represents the system response with a uniform distribution applied to the $\mathrm{k} \_$factor during the Monte Carlo Simulation for PANI-based LSP layer. 
TOGW Baseline (lbs)

145800151200156600162000167400 142800147900153000158100163200
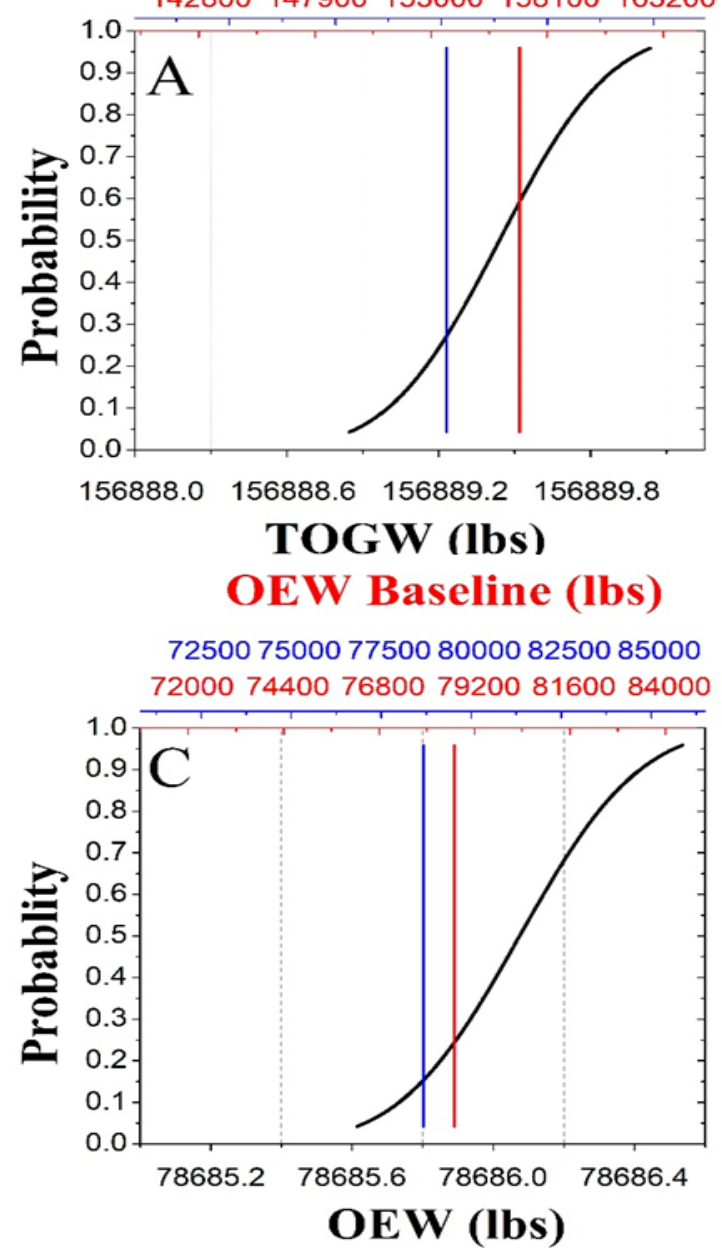

Fuel Weight Baseline (lbs)

435004500046500480004950051000

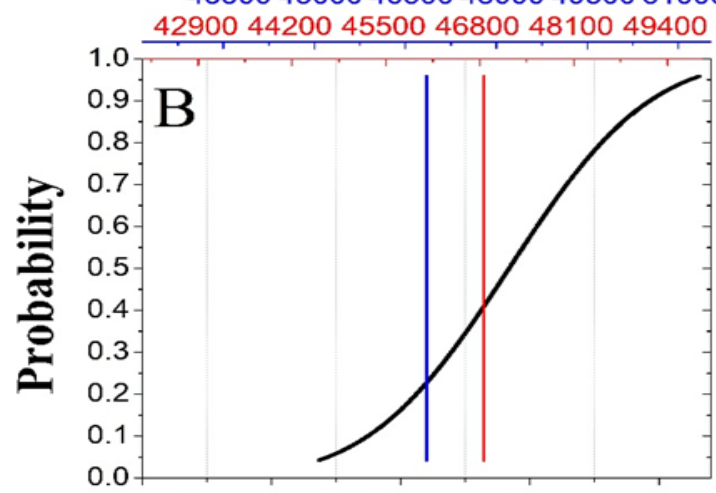

$46853.246853 .3 \quad 46853.4 \quad 46853.5 \quad 46853.6$

Fuel Weight (lbs)

W/S Baseline (lb/ft^2)

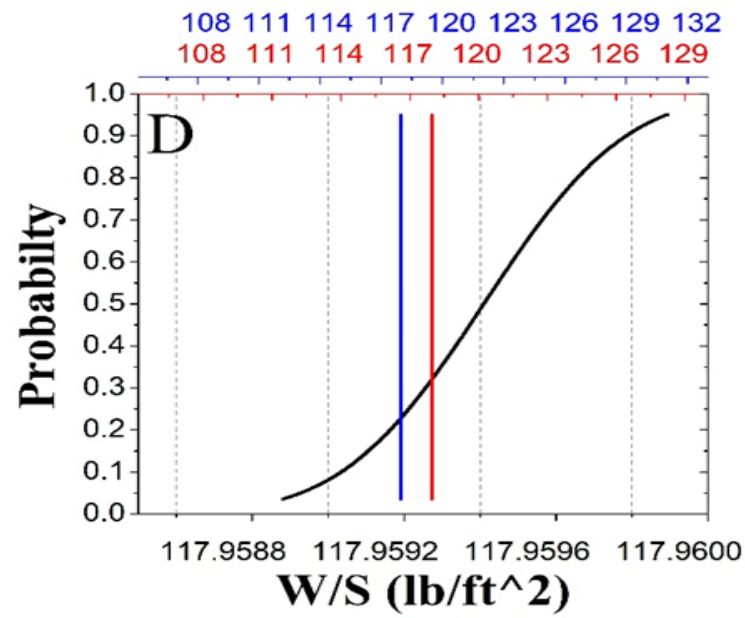

$\mathbf{W} / \mathbf{S}\left(\mathbf{l b} / \mathbf{f t}^{\wedge} \mathbf{2}\right)$

Thrust Baseline (lbs)

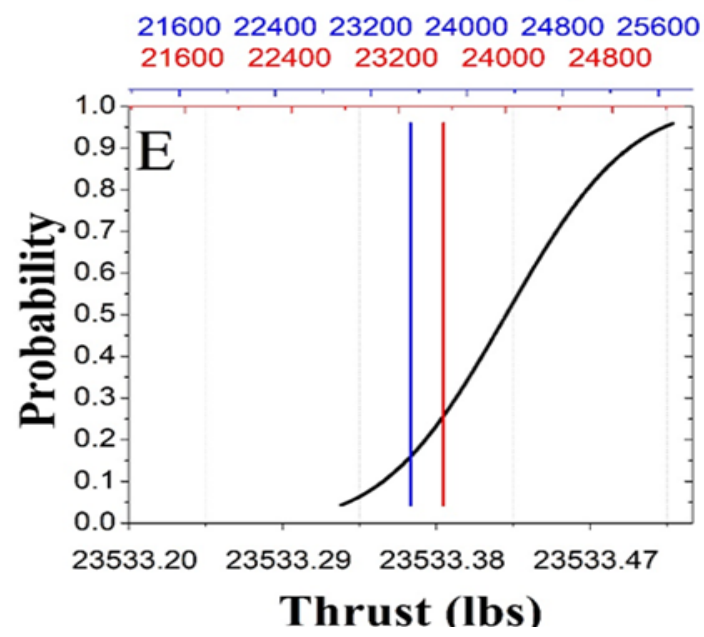

Fig. 5 Resulting CDF for PANI-based LSP layer for aircraft size responses: a) takeoff gross weight, b) fuel weight, c) operating empty weight, d) wing loading, and e) engine thrust. 
Table 5 and Table 6 lists the quantitative results of aircraft weight and size that are affected by infusing PANIbased LSP layer technology on aircraft systems. The benefit or penalty caused by the proposed new technology can be reflected by change of probability values with respect to its baseline. The traditional metal mesh baseline value was calculated based on the use of metal copper mesh (areal weight $0.04 \mathrm{lb} / \mathrm{ft}^{\wedge} 2$ [29]) with structural adhesive film $\left(0.05 \mathrm{lb} / \mathrm{ft}^{\wedge} 2[30]\right)$. The baseline value of expanded metal foil was calculated based on the use of expanded copper foil (areal weight $0.029 \mathrm{lb} / \mathrm{ft}^{\wedge} 2$ [31]) with structural adhesive film $\left(0.05 \mathrm{lb} / \mathrm{ft}^{\wedge} 2[30]\right)$. An $80 \%$ confidence level has been selected to be a reasonable expectation level, and confidence levels $50 \%$ and $20 \%$ were presented for comparison.. The confidence level is related to the risk or uncertainty associated with this technology and the selection of these levels is purely subjective [32]. Each column gives the probability of achieving at least the value given, which is stated as percentage of change from the baseline. It is the decision-maker's discretion to decide what level of risk they willing to absorb in the early stages of design. A low confidence level implies that application of this new technology would be a risky since the desired impact has high probability of not being achieved.

As can be seen from Table 5, compare to metal mesh LPS, the introduction of PANI based LPS demonstrates a slight weight reduction in responses associated with aircraft size. This new technology reduced the baseline take-off gross weight (TOGW) by $0.004 \%$ to $156889.8 \mathrm{lbs}$ with $80 \%$ probability. For operating empty weight (OEW), the maximum weight reduction could be achieved by about $0.006 \%$. As expected, fuel weight (Fuel WT) and the engine thrust (THRUST) were also influenced by a reduction in TOGW and OEW, yet very slightly. Finally, the wing loading (W/S) was decreased which can be due to the wing weight reduction compare to use metal mesh. In light of this, our result suggests the use of PANI-based LSP layer may offer a marginal benefit in aircraft weight and size compared to the traditional metal mesh based LSP. 
Table 5 The aircraft weight and size responses for using PANI-based LSP layer on aircraft system after TIF analysis (compared with metal copper mesh as baseline).

\begin{tabular}{|c|c|c|c|c|c|c|c|}
\hline \multirow{2}{*}{$\begin{array}{l}\text { System Responses for aircraft } \\
\text { size }\end{array}$} & \multirow{2}{*}{$\begin{array}{c}\text { Baseline } \\
\text { (Metal } \\
\text { Mesh) }\end{array}$} & \multicolumn{6}{|c|}{ Results for using PANI-based LSP layer } \\
\hline & & $\begin{array}{l}80 \% \\
\text { Prob. }\end{array}$ & $\%$ diff & $\begin{array}{l}50 \% \\
\text { Prob. }\end{array}$ & $\% \operatorname{diff}$ & $\begin{array}{l}20 \% \\
\text { Prob. }\end{array}$ & $\%$ diff \\
\hline Take-off Gross Weight(lb) & 156895.4 & 156889.8 & $0.00 \%$ & 156889.4 & $0.00 \%$ & 156889.1 & $0.00 \%$ \\
\hline Operating Empty Weight (lb) & 78690.6 & 78686.3 & $-0.01 \%$ & 78686.1 & $-0.01 \%$ & 78685.8 & $-0.01 \%$ \\
\hline Fuel Weight (lb) & 46854.8 & 46853.6 & $0.00 \%$ & 46853.5 & $0.00 \%$ & 46853.4 & $0.00 \%$ \\
\hline Wing Loading $\left(\mathrm{lb} / \mathrm{ft}^{\wedge} 2\right)$ & 117.97 & 117.96 & $-0.01 \%$ & 117.96 & $-0.01 \%$ & 117.96 & $-0.01 \%$ \\
\hline Engine Thrust (lb) & 23534.3 & 23533.5 & $0.00 \%$ & 23533.4 & $0.00 \%$ & 23533.4 & $0.00 \%$ \\
\hline
\end{tabular}

The quantitative impacts of using PANI-based LSP layer have been listed in Table 6 . The expanded copper foil has been used as baseline. Compare to expanded copper foil, the use of PANI-based LSP layer leads to a slight penalty on the take-off gross weight (TOGW) $(0.01 \%$ from the baseline). This result is also true for engine thrust. The impact on operating empty weight (OEW) is $0.016 \%$ from baseline. While the penalties on the fuel weight and on the wing loading with this new technology is much lower. Today, metal mesh and expanded metal foil are still the first choice of LSP solution due to their high specific electrical conductivity. Although PANI-based LSP offers desirable anticorrosion properties with negligible impact to the aircraft weight and size, it may require further development before putting into practical applications due to its much lower conductivity performance than metal- based LSP.

Table 6 The aircraft weight and size responses for using PANI-based LSP layer on aircraft system after TIF analysis (Compared with expanded copper foil as baseline).

\begin{tabular}{|c|c|c|c|c|c|c|c|}
\hline \multirow{2}{*}{$\begin{array}{c}\text { System Responses for aircraft } \\
\text { size }\end{array}$} & \multirow{2}{*}{$\begin{array}{c}\text { Baseline } \\
\text { (Expanded } \\
\text { Foil) }\end{array}$} & \multicolumn{6}{|c|}{ Results for using PANI-based LSP layer } \\
\cline { 5 - 8 } & $\begin{array}{c}80 \% \\
\text { Prob. }\end{array}$ & $\%$ diff & $\begin{array}{c}50 \% \\
\text { Prob. }\end{array}$ & $\%$ diff & $\begin{array}{c}20 \% \\
\text { Prob. }\end{array}$ & $\%$ diff \\
\hline Take-off Gross Weight(lbs) & 156873.8 & 156889.8 & $0.01 \%$ & 156889.4 & $0.01 \%$ & 156889.1 & $0.01 \%$ \\
\hline Operating Empty Weight $(\mathrm{lbs})$ & 78673.9 & 78686.4 & $0.02 \%$ & 78686.1 & $0.02 \%$ & 78685.8 & $0.02 \%$ \\
\hline Fuel Weight $(\mathrm{lbs})$ & 46849.8 & 46853.6 & $0.01 \%$ & 46853.5 & $0.01 \%$ & 46853.4 & $0.01 \%$ \\
\hline Wing Loading $\left(\mathrm{lbs} / \mathrm{ft}^{\wedge} 2\right)$ & 117.95 & 117.96 & $0.01 \%$ & 117.96 & $0.01 \%$ & 117.96 & $0.01 \%$ \\
\hline Engine Thrust $(\mathrm{lbs})$ & 23531.1 & 23533.5 & $0.01 \%$ & 23533.4 & $0.01 \%$ & 23533.4 & $0.01 \%$ \\
\hline
\end{tabular}


Economic viability of the proposed technology is quantified in terms of potential cost with respect to the budget limit. Figure 6 shows the resulting cumulative probability distributions for aircraft cost responses as a result of the new technology infusion. In Fig. 6, the red and blue lines indicate two different baselines (the initial value of the system response) for traditional metal mesh and expanded metal foil, respectively. The black line represents the system response with a uniform distribution applied to the $\mathrm{k}_{-}$factor during the Monte Carlo Simulation for PANI-based LSP layer. 

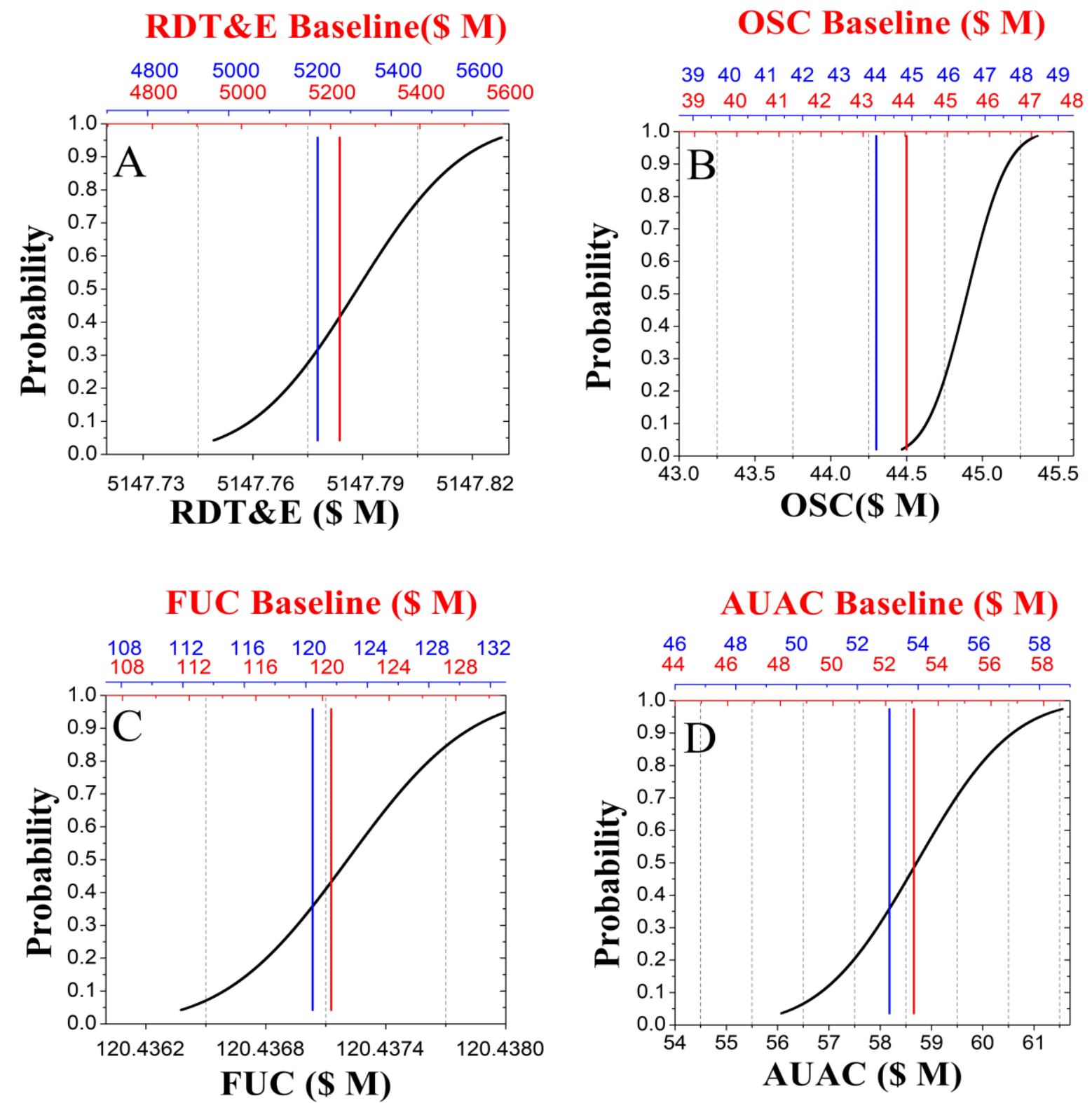

Fig. 6 Resulting CDF for PANI-based LSP layer for aircraft on a) research, development, testing, and evaluation cost; b) operation support cost; c) first unit cost; and d) average unit airplane cost. (\$ M represents millions of U.S. dollars.) 
The economic viability assessment was performed in the same manner as the technical feasibility above. The baseline in Table 7 is copper metal mesh and Table 8 expanded copper foil. The cost of materials was obtained from the supplier's quotation. Similar to Table 5 and Table 6, $80 \% 50 \%, 20 \%$ confidence levels were presented for comparison.

As evident from Table 7, compare to metal mesh, the infusion of the new technology in wing structure has not only improved the aircraft weight and size, but also reduced some the system cost and economic risk. By using this new technology, the designer can save up to $1.39 \%$ in research, development, testing and evaluation cost (RDT\&E) with $80 \%$ probability. Due to reduced materials cost, the first unit cost (FUC) is more likely to be reduced by about $0.07 \%$. However, its relatively new manufacturing and repair process increases the operation and maintenance cost by about $2.45 \%$. Similar trends were found for average unit airplane cost (AUAC), it is more likely to be increased by $13.47 \%$ to 60.2 U.S. dollars (USD)due to its impact on labor learning curves (k_LEARN and k_LEARNAS) associated with new manufacturing methodology. Therefore, using PANI-based LSP layer instead of metal mesh in wing structure help to reduce the RDT\&E cost and first unit cost, but at a compromise of increased operation support cost and average unit cost.

Table 7 The aircraft cost responses for using PANI-based LSP layer on aircraft system after TIF analysis with metal copper mesh baseline).

\begin{tabular}{|c|c|c|c|c|c|c|c|}
\hline \multirow{2}{*}{ System Responses for aircraft cost } & \multirow{2}{*}{$\begin{array}{c}\text { Baseline } \\
\text { (Metal }\end{array}$} & \multicolumn{6}{|c|}{ Results for using PANI-based LSP layer } \\
\cline { 3 - 8 } & Mesh) & $\begin{array}{c}80 \% \\
\text { Prob. }\end{array}$ & $\%$ diff & $\begin{array}{c}50 \% \\
\text { Prob. }\end{array}$ & $\%$ diff & $\begin{array}{c}20 \% \\
\text { Prob. }\end{array}$ & $\%$ diff \\
\hline RDT\&E (M\$) & 5220.2 & 5147.8 & $-1.39 \%$ & 5147.8 & $-1.39 \%$ & 5147.7 & $-1.39 \%$ \\
\hline Operation Support Cost (M\$) & 44.03 & 45.1 & $2.45 \%$ & 44.9 & $1.98 \%$ & 44.7 & $1.50 \%$ \\
\hline First Unit Cost (M\$) & 120.5 & 120.4 & $-0.07 \%$ & 120.4 & $-0.07 \%$ & 120.4 & $-0.07 \%$ \\
\hline Average Unit Airplane Cost (M\$) & 53.1 & 60.2 & $13.47 \%$ & 58.7 & $10.57 \%$ & 57.2 & $7.78 \%$ \\
\hline
\end{tabular}

Similar impact can be found in the case of expanded copper foil, see Table 8. The reduction in research, development, testing and evaluation cost (RDT\&E) costs is evitable (-1.36\%). Due to the increased labour hour required for the complex manufacture and repair process, a more significant increase in operation support cost (OSC) 
of $2.48 \%$ is evident. A slight decrease of $0.01 \%$ is also seen for the first unit cost (FUC). The probability of increasing average unit airplane cost of 60.22 U.S. dollars (USD)is $80 \%$. Therefore, the analysis suggests that using PANI-based LSP layer as LSP solution is less economical compared to the expanded copper foil.

Table 8 The aircraft cost response for using PANI-based LSP layer on aircraft system fter TIF analysis with expanded copper foil baseline.

\begin{tabular}{|c|c|c|c|c|c|c|c|}
\hline \multirow{2}{*}{$\begin{array}{c}\text { System Responses for aircraft } \\
\text { cost }\end{array}$} & \multirow{2}{*}{$\begin{array}{c}\text { Baseline } \\
\text { Expanded } \\
\text { Foil) }\end{array}$} & \multicolumn{5}{|c|}{ Results for using PANI-based LSP layer } \\
\cline { 5 - 9 } & $\begin{array}{c}80 \% \\
\text { Prob. }\end{array}$ & $\%$ diff & $\begin{array}{c}50 \% \\
\text { Prob. }\end{array}$ & $\%$ diff & $\begin{array}{c}20 \% \\
\text { Prob. }\end{array}$ & $\%$ diff \\
\hline RDT\&E (M\$) & 5218.66 & 5147.81 & $-1.36 \%$ & 5147.79 & $-1.36 \%$ & 5147.77 & $-1.36 \%$ \\
\hline Operation Support Cost (M\$) & 44.02 & 45.11 & $2.48 \%$ & 44.9 & $2.00 \%$ & 44.69 & $1.52 \%$ \\
\hline First Unit Cost (M\$) & 120.45 & 120.44 & $-0.01 \%$ & 120.44 & $-0.01 \%$ & 120.44 & $-0.01 \%$ \\
\hline Average Unit Airplane Cost (M\$) & 53.06 & 60.22 & $13.49 \%$ & 58.68 & $10.59 \%$ & 57.2 & $7.80 \%$ \\
\hline
\end{tabular}

\section{III.Conclusion}

This paper presents an initial study on the feasibility of using TIF to explore the impact of infusing a low TRL technology (PANI-based conductive polymer as a potential LSP solution) in a representative commercial aircraft wing system. The results show that the novel LSP technology can effectively increase the electrical conductivity of composites in the thickness direction, but its electrical conductivity is still not good as metal-based material. In terms of weight saving, the expanded metal foil is considered the best candidate, followed by the novel LSP technology and the metal mesh. From economic perspective, the proposed new technology could lead to greater profitability in research, development, testing and evaluation cost. Yet, the costs associated with manufacturing and maintenance this material was more than the use of metal mesh and expanded metal foil. It is acknowledged that low TRL technologies are characterized by a lack of complete knowledge, with few Subject Matter Experts (SMEs) in the field, and very little, if any, laboratory results or experimental data. These characteristics increase the degree of difficulty to model and identify the $\mathrm{k}$ _factors associated with addition of a new technology. Despite of this limitation, the methodology proposed in this study could be generalized and may be adopted by future designers to assist their decision-making process in aircraft design with new material consideration. It is expected that with more experimental data/knowledge made available in the future, manipulated shape function can be assigned for predictions with better accuracy. 


\section{Funding Sources}

\section{This work was supported by (1)European Office of Aerospace Research and Development (EOARD); Award no. FA 9550-17-1-0020}

\section{References}

[1] Gupta G, Kumar A, Tyagi R, et al. "Application and Future of Composite Materials: A Review." International Journal of Innovative Research in Science, Engineering and Technology, 2016, 5(5): 6907-6911

[2] G. N. Szatkowski, T. X. Nguyen, S. V Koppen, J. J. Ely, and J. J. Mielnik, "Electrical Characterizations of Lightning Strike Protection Techniques for Composite Materials," NASA Publication, September 2009

[3] Feraboli, P., and Kawakami, H., "Damage of Carbon/Epoxy Composite Plates Subjected to Mechanical Impact and Simulated Lightning Strike," Journal of Aircraft, Vol. 47, No. 3, 2010, pp. 9991012.https://doi.org/10.2514/1.46486

[4] Ogasawara, T., Hirano, Y., and Yoshimura, A., "Coupled Thermal-Electrical Analysis for Carbon Fiber/Epoxy Composites Exposed to Simulated Lightning Current," Composites Part A: Applied Science and Manufacturing, Vol. 41, No. 8, 2010, pp. 973-981. https://doi.org/10.1016/j.compositesa.2010.04.001

[5] Gagné, M., and Therriault, D., "Lightning Strike Protection of Composites," Progress in Aerospace Sciences, Vol. 64, Jan. 2014, pp. 1-16. https://doi.org/10.1016/j.paerosci.2013.07.002

[6] Jacob,A., “AirbusA350XWBUndergoes Lightning Strike Testing,”Materials Today (online journal), 8 May 2013, https://www.materialstoday.com/ composite-applications/news/airbus-a350-xwb-undergoes-lightningstriketesting/ [retrieved 22 Dec. 2019].

[7] Bailey, J., "Safety Of The 787 Dreamliner During A Lightning Strike Called Into Question,” Simple Flying (online journal), 13 Dec. 2019, https://simpleflying.com/787-dreamliner-lightning-safety/ [retrieved 22 Dec. 2019].

[8] G. Gardiner. Lightning strike protection for composite structures, 2006. https://www.compositesworld.com/articles/lightning-strike-protection-for-composite-structures [retrieved 22 Dec. 2019].

[9] Katunin, A., Krukiewicz, K., Turczyn, R., Sul, P., and Dragan, K., "Lightning Strike Resistance of an Electrically Conductive CFRP with a CSA-Doped PANI/Epoxy Matrix," Composite Structures, Vol. 181, 
Dec. 2017, pp. 203-213. https://doi.org/10.1016/j.compstruct.2017.08.091

[10] Yokozeki,T.,Goto,T.,Takahashi,T.,Qian,D., Itou, S.,Hirano,Y., Ishida, Y., Ishibashi,M., andOgasawara, T., "Development and Characterization of CFRP Using a Polyaniline-Based Conductive Thermoset Matrix," Composites Science and Technology, Vol. 117, Sept. 2015, pp. $277-281$. https://doi.org/10.1016/j.compscitech.2015.06.016

[11] Katunin, A., Krukiewicz, K., Turczyn, R., Sul, P., and Bilewicz, M., "Synthesis and Characterization of the Electrically Conductive Polymeric Composite for Lightning Strike Protection of Aircraft Structures," Composite Structures, Vol. 159, Jan. 2017, Paper 773-783. https://doi.org/10.1016/j.compstruct.2016.10.028

[12] Hirano, Y., Yokozeki, T., Ishida, Y., Goto, T., Takahashi, T., Qian, D., Ito, S., Ogasawara, T., and Ishibashi, M., "Lightning Damage Suppression in a Carbon Fiber-Reinforced Polymer with a Polyaniline-Based Conductive Thermoset Matrix," Composites Science and Technology, Vol. 127, April 2016, pp. 1-7. https://doi.org/10.1016/j.compscitech.2016.02.022

[13] Katunin, A., Krukiewicz, K., Herega, A., and Catalanotti, G., “Concept of a Conducting Composite Material for Lightning Strike Protection," Advances in Materials Science, Vol. 16, No. 2, 2016, pp. 32-46. https://doi.org/10.1515/adms-2016-0007

[14] Guo, Y., Xu, Y., Wang, Q., Dong, Q., Yi, X., and Jia, Y., "Enhanced Lightning Strike Protection ofCarbon Fiber Composites UsingExpanded Foils with Anisotropic Electrical Conductivity," Composites Part A: Applied Science and Manufacturing, Vol. 117, Feb. 2019, pp. 211-218. https://doi.org/10.1016/j.compositesa.2018.11.022

[15] Kumar,V., Tomohiro, Y., Takao, O., Hirano, Y., Goto, T., Takahashi, T., Hassen, A. A., and Ogasawara, T., "Polyaniline-Based All-Polymeric Adhesive Layer: An Effective Lightning Strike Protection Technology for High Residual Mechanical Strength of CFRPs," Composites Science and Technology, Vol. 172, March 2019, pp. 49-57. https://doi.org/10.1016/j.compscitech.2019.01.006

[16] Soban, D. S., and Mavris, D. N., “Assessing the Impact of Technology on Aircraft Systems Using Technology Impact Forecasting," Journal of Aircraft, Vol. 50, No. 5, 2013, pp. 1380-1393. https://doi.org/10.2514/1.C031871

[17] Mavris, D. N., Baker, A. P., and Schrage, D. P., "Implementation of a Technology Impact Forecast Technique on a Civil Tiltrotor," Presented at the American Helicopter Society 55th Annual Forum, Montreal, Quebec, 
Canada,May 25-27, 1999. AHS-99-AB.Vol. 2, pp. 1570-82.https://doi.org/10.1017/CBO9781107415324.004

[18] McCullers, L. A., Flight Optimization System, Computer Program and Users Guide, Version 5.7, NASA Langley Research Center, Hampton, VA, Dec. 1994.

[19] Galloway, T. L., and Mavris, D. N., Aircraft Life Cycle Cost Analysis (ALCCA) Program, NASA Ames Research Center, Moffett Field, CA, Sept. 1993.

[20] Kumar, V., Yokozeki, T., Goto, T., and Takahashi, T., "Synthesis and Characterization of PANI-DBSA/DVB Composite Using Roll-Milled PANI-DBSAComplex,” Polymer,Vol. 86, March 2016, Paper 129e137. https://doi.org/10.1016/j.polymer.2016.01.054

[21] “Airbus A320-Aerospace Technology," Online Article. https://www.aerospacetechnology.com/projects/a320/ [retrieved 27 Dec 2019]

[22] A. Quilter, Composites in aerospace applications. In IHS White Paper; IHS Corporate: Englewood, CO, USA,2001; Volume 444.http://uk.ihs.com/products/white-papers. [retrieved 15 Dec. 2019].

[23] Kingsley-Jones,M., "Dubai 09: A320's Sharklets to Deliver 3.5\%Lower Fuel Burn from2012," Flight Daily News (online journal), 15Nov. 2009, https://www.flightglobal.com/news/articles/dubai-09-a320s-sharkletstodeliver- 35-lower-fuel-burn-from-2012-334945/ [retrieved 30March 2019].

[24] “Winglets and Sharklets," Flying Engineer(online journal), http://theflyingengineer.com/flightdeck/wingletsand-sharklets/ [retrieved 30 March 2019].

[25] Soban, D. S., and Zeune, C., “Technology Assessment for a Complex Aircraft System Using Technology Scenarios," Journal of Defense Modeling and Simulation: Applications, Methodology, Technology,Vol. 12, No. 3, 2015, pp. 305-318.https://doi.org/10.1177/1548512914540230

[26] Kirby, M.R., Mavris, D.N., "Forecasting the Impact of Technology Infusion on Subsonic Transport Affordability", AIAA 98-5576.

[27] Alberth,S., "Forecasting Technology Costs via theLearning Curve-Myth or Magic?" International Inst. For Applied Systems Analysis Interim Report. IR-06-058, Laxenburg, Austria, 2006. https://doi.org/10.17863/CAM.5166

[28] JMPComputer Program and Users Manual, SAS Inst., Cary, NC, 1994

[29] Astroseal Production List Brochure. Astrostrike ${ }^{\circledR}$ Premier Lightning Strike Protection by Astroseal Products Manufacturig Corp., http://www.astrosealproducts.com/product_codes.html [retrieved 15 Dec 2019]. 
[30] 3M, “3M Scotch-Weld ${ }^{\mathrm{TM}}$ Structural Adhesive Film AF555 Technology Data Sheet,” Bracknell, U.K., 2007, pp. 1-15, https://www.3m.com/3M/en_US/ company-us/all-3m-products/ /3M-Scotch-Weld-StructuralAdhesive-Film- AF-555/?N=5002385+3292667642\&rt=rud [retrieved 15 Dec. 2019].

[31] "Expanded Material Technology Data Sheet," Dexmet, https://www .dexmet.com/expanded-metals [retrieved 10 Dec. 2019].

[32] Mavris, D. N., and Kirby, M. R., “Technology Identification, Evalu- ation, and Selection for Commercial Transport Aircraft,” Society of AlliedWeight Engineers, SAWE Paper 2456, San Jose, CA, May 1999. 